\title{
Growth differentiation factor 9 gene variants in Sudanese desert sheep ecotypes
}

\author{
A.S. Ali ${ }^{1}$, M.T. Ibrahim ${ }^{1}$, M.M. Mohammed ${ }^{1}$, A.A. Elobied ${ }^{1}$ \& G. Lühken ${ }^{2 \#}$ \\ ${ }^{1}$ College of Animal Production Science and Technology, Sudan University of Science and Technology, Khartoum, North- \\ Sudan \\ ${ }^{2}$ Department of Animal Breeding and Genetics, Justus Liebig University, Giessen, Germany
}

(Received 8 March 2016; Accepted 7 September 2016; First published online 12 November 2016)

\begin{abstract}
Copyright resides with the authors in terms of the Creative Commons Attribution 2.5 South African Licence. See: http://creativecommons.org/licenses/by/2.5/zaCondition of use: The user may copy, distribute, transmit and adapt the work, but must recognise the authors and the South African Journal of Animal Science.
\end{abstract}

\begin{abstract}
Certain variants in the growth differentiation factor 9 (GDF9) gene have major effects on the ovulation rate in sheep. The aim of this study was to analyse GDF9 variability in the Sudanese desert sheep ecotypes Ashgar, Dubasi and Watish, and to test identified variants for association with litter size. For this purpose, ewes of these ecotypes with litter size records for at least two litters were sampled. The complete GDF9 exon 2 was sequenced in a total of 28 ewes. An additional variant in exon 1 (c260G>A) was genotyped by restriction-length polymorphism analysis in 97 ewes. Differences in genotype and allele frequencies of polymorphic positions between two groups differing in litter size (only a single lamb versus more than a single lamb) were tested for significance using Fisher's exact test. GDF9 exon 2 variants c.477G>A and c.721G>A and exon 1 variant c.260G $>A$ were found to be polymorphic in all three sheep ecotypes. Exon 2 variants $c .471 \mathrm{C}>\mathrm{T}$ and $\mathrm{c} .978 \mathrm{~A}>\mathrm{G}$ were polymorphic in at least one ecotype. No significant associations were observed between allele and genotype frequencies of identified variants and litter size. This suggests that GDF9 variants influencing ovulation are absent in these Sudanese sheep ecotypes, and therefore cannot be used to increase litter size within this population of sheep.
\end{abstract}

Keywords: Ashgar, Dubasi, fecundity, litter size, ovine fertility, Watish

\# Corresponding author: gesine.luehken@agrar.uni-giessen.de

\section{Introduction}

The growth differentiation factor 9 (GDF9) gene is located on chromosome 5 and contains two exons, divided by an intron of 1126 base pairs. The exons code for a propeptide with 453 amino acids (Bodensteiner et al., 1999).

GDF9 belongs to the transforming growth factor $\beta$ superfamily, and has a vital role in ovarian follicular development and ovulation rate. It has been widely studied in humans, sheep, and goats (Elvin et al., 1999; McNatty et al., 2005). In sheep, numerous mutations in the GDF9 coding sequence have been reported, with one single exception all of them being located in the second exon (Table 1). Eight of these 11 single nucleotide polymorphisms (SNPs) cause amino acid substitutions, and some of them have an effect on ovulation rate and hence litter size. The three non-synonymous SNPs c.943C > T, c.1184C >T and c.1279A>C result in a phenotype of increased ovulation rate/litter size in heterozygous ewes, and infertility linked to hypoplasia of ovary and uterus in homozygous females (Hanrahan et al., 2004; Juengel et al., 2013; Nicol et al., 2009; Souza et al., 2014). Infertility due to the homozygous mutant genotype was not observed for two other non-synonymous SNPs, c.1111G>A (Vage et al., 2013) and C.1034C>T (Silva et al., 2011), which instead show an additive effect on ovulation rate and litter size.

As only the mature GDF9 peptide is deemed biologically active (Paulini \& Melo, 2011), mutations that are located proximal to the RRHR furin protease cleavage site (proximal to amino acid position 318) are regarded as not affecting the protein function (Hanrahan et al., 2004). A single non-synonymous SNP in exon 1 (c.260G $>A$ ) is located before the furin cleavage site, and causes only a conservative substitution of amino acids (Arg87His) (Hanrahan et al., 2004). However, this GDF9 mutation was claimed by Barzegari et al. (2010) to be associated with infertility (genotype AA), and at least in combination with another mutation in the gene coding for the bone morphogenic protein 15 (BMP15) with higher ovulation rate (genotype $A G)$ in Iranian sheep.

Associations of GDF9 sequence variants at positions with no obvious impact on the gene function might be due to a linkage with undetected or until now not tested causal variants. Such a linkage was recently speculated by Albarella et al. (2015) for a silent G>A substitution they detected for the first time at 
position 750 of GDF9 in Bagnolese sheep. They observed a higher litter size in sheep with the genotype GG compared with AG $(P<0.05)$. The effect of the genotype AA was not tested because of its low frequency.

Table 1 Published sequence variants in the coding region of ovine GDF9

\begin{tabular}{|c|c|c|c|c|}
\hline $\begin{array}{l}\text { Position in } \\
\text { coding sequence }\end{array}$ & Variant name(s) & $\begin{array}{l}\text { Amino acid } \\
\text { change }\end{array}$ & Breed & Variant first published by \\
\hline \multicolumn{5}{|l|}{ Exon 1} \\
\hline c. $260 \mathrm{G}>\mathrm{A}$ & G1 & p.Arg87His & Cambridge \& Belclare & Hanrahan et al., (2004) \\
\hline \multicolumn{5}{|l|}{ Exon 2} \\
\hline c. $471 \mathrm{C}>\mathrm{T}$ & G2 & p.Val157Val & Cambridge \& Belclare & Hanrahan et al., (2004) \\
\hline c. $477 \mathrm{G}>\mathrm{A}$ & G3 & p.Leu159Leu & Cambridge \& Belclare & Hanrahan et al., (2004) \\
\hline c. $531 \mathrm{C}>\mathrm{T}$ & & p.Asn177Asn & Bagnolese & Albarella et al., (2015) \\
\hline c. $617 \mathrm{G}>\mathrm{A}$ & & p.Arg206Lys & Laticauda & Albarella et al., (2015) \\
\hline c. $721 \mathrm{G}>\mathrm{A}$ & G4 & p.Glu241Lys & Cambridge \& Belclare & Hanrahan et al., (2004) \\
\hline c. $729 \mathrm{G}>\mathrm{T}$ & & p.Gln243His & Small Tail Han & Chu et al., (2011) \\
\hline c. $750 \mathrm{G}>\mathrm{A}$ & & p.Arg250Arg & Thoka & Nicol et al., (2009) \\
\hline c. $943 \mathrm{C}>\mathrm{T}$ & $\mathrm{FecG}^{\mathrm{V}}$ & p.Arg315Cys & Ile de France & Souza et al., (2014) \\
\hline c. $953 G>T$ & & p.Arg318lle & Bagnolese & Albarella et al., (2015) \\
\hline c. $978 A>G$ & G5 & p.Glu326Glu & Cambridge \& Belclare & Hanrahan et al.,(2004) \\
\hline c. $994 G>A$ & G6 & p.Val332lle & Cambridge \& Belclare & Hanrahan et al.,(2004) \\
\hline c. $1034 C>T$ & $\mathrm{FecG}^{\mathrm{SI}} / \mathrm{FecG}^{\mathrm{E}}$ & p.Phe345Cys & Brazilian Santa Inês & Silva et al., (2011) \\
\hline c. $1111 \mathrm{G}>\mathrm{A}$ & G7 & p.Val371Met & Cambridge \& Belclare & Hanrahan et al., (2004) \\
\hline c. $1184 C>T$ & $\mathrm{G} 8 / \mathrm{FecG}^{\mathrm{H}}$ & p.Ser395Phe & Cambridge \& Belclare & Hanrahan et al., (2004) \\
\hline c. $1203 G>A$ & & p.Val401Val & Bagnolese & Albarella et al., (2015) \\
\hline C. $1279 A>C$ & $\mathrm{Fec}^{\top}$ & p.Ser427Arg & Thoka & Nicol et al., (2009) \\
\hline c. $1358 \mathrm{G}>\mathrm{A}$ & & p.Arg453His & Laticauda & Albarella et al., (2015) \\
\hline
\end{tabular}

Sheep population in Sudan consists of about 39.6 million, representing $37.79 \%$ of the total Sudanese livestock population, which is approximately 104 million head. In recent years there has been growing interest in exporting desert-type Sudanese sheep to Arab countries (Ministry of Animal Resources, Fisheries and Ranges (MARFR), 2013). Desert sheep is one of the most widely distributed types in Sudan, representing about $65 \%$ of the total sheep population, and comprising seven regional ecotypes, namely Gezira (Ashgar and Dubasi), Watish, Butana, Bija, Meidob, and North Riverine Wooled Sheep (Mukhtar, 1985; El Hag et al., 2001). Sulieman et al. (1990) found that Ashgar produced higher numbers of lambs per ewe (1.30) than Dubasi (1.18) and Watish (1.17).

The aim of this work was to analyse GDF9 gene variability in the Sudanese desert sheep ecotypes Ashgar, Dubasi and Watish, and to test identified variants for association with litter size.

Ewes from the three sheep ecotypes (Figure 1) from various regions of Sudan were selected for sampling according to their history of litter size (River Nile and Khartoum states for Ashgar, Gazira state for Dubasi and Sinar state for Watish). Any selected ewe must have had at least two lambing records. The number of lambing records ranged from two to seven (on average 3.9 records). 


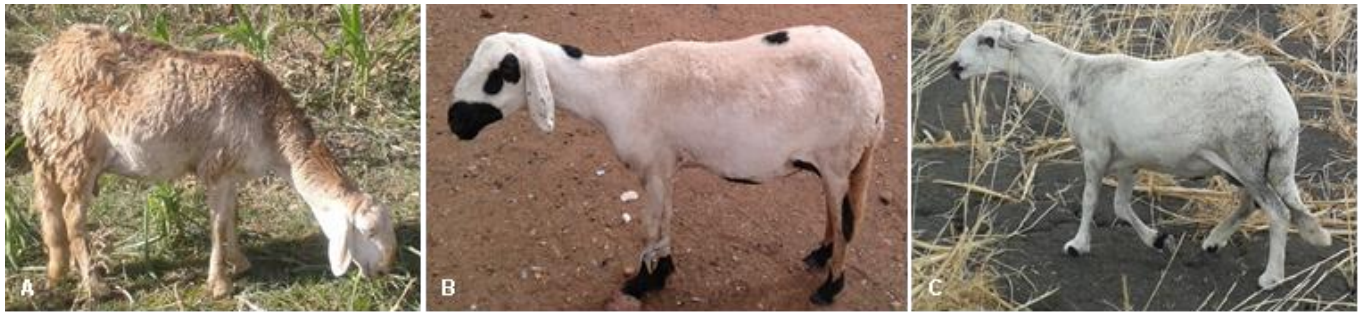

Figure 1 Sudanese desert sheep ecotypes analysed in this study: A) Ashgar; B) Dubasi; C Watish

Ewes were divided into two groups according to their average litter size. One group comprised ewes of all three ecotypes that gave birth to single lambs in all recorded lambings (hence the average of litter size was 1.0). The other group included ewes of all three ecotypes, which on average had more than a single lamb (average litter size per ewe in this group ranged from 1.5 to 3.0; the average litter size of the whole group was 2.1).

Blood samples $(5 \mathrm{~mL})$ were drawn from the jugular vein in EDTA vacutainer tubes. The genomic DNA was extracted from white blood cells according to Montgomery \& Sise (1990).

Sampling of sheep was approved by the Federal Ministry of Animal Resources, Fishery and Ranges of North Sudan and in compliance with standard ethical norms.

To identify sequence variants in the second exon of GDF9, 28 samples were sequenced: 10 DNA samples each from Ashgar and Dubasi and eight from Watish. For each ecotype, 50\% of the samples were selected from the single lamb group and the other $50 \%$ from the more than a single lamb group. To amplify two overlapping fragments covering the complete exon 2 of GDF9, these pairs of primers were designed using GenBank sequence AF078545.2 and the software Primer3 (Untergrasser et al., 2012): forward primer 5'-GGCTTGAGAATGTGGGGAGAA-3' and reverse primer 5'-GGGACGATCTTACACCCTCA-3' to amplify a proximal fragment of $656 \mathrm{bp}$, and forward primer 5'-CACAAGTGCTCAGGCTTTTC-3' and reverse primer 5'CATGAGGAAGGCAGCTGTTA-3' to amplify an overlapping distal fragment of $749 \mathrm{bp}$. Polymerase chain reaction (PCR) amplifications were carried out in a final volume of $50 \mu \mathrm{L}$, including $0.2 \mathrm{mM} \mathrm{dNTPs}, 1 \mathrm{mM}$ $\mathrm{MgCl}_{2}, 20 \mathrm{pmol}$ of each primer, $1.5 \mathrm{U}$ Go Taq Flexi Polymerase in 1-fold Colourless GoTaq Flexi buffer (Promega, Madison, Wis, USA) and $50 \mathrm{ng}$ of DNA template. PCR reaction was run in a thermal cycler under these conditions: initial denaturation at $95^{\circ} \mathrm{C}$ for $90 \mathrm{sec}$, followed by 35-40 cycles consisting of denaturation at $95^{\circ} \mathrm{C}$ for $15 \mathrm{sec}$, annealing at $65^{\circ} \mathrm{C}$ for $30 \mathrm{~s}$, extension at $72{ }^{\circ} \mathrm{C}$ for $60 \mathrm{~s}$, and a final extension at $72{ }^{\circ} \mathrm{C}$ for 5 min. Agarose gel electrophoresis and Nanodrop 2000 spectrophotometer (VWR International GmbH, Erlangen, Germany) were used to check PCR products for size, quality and quantity. PCR products were purified and then sequenced using Big Dye Terminator chemistry and the ABI 3130 Genetic Analyzer as recommended by the manufacturer (Applied Biosystems, Foster City, Calif, USA) with PCR forward primer (656-bp fragment) and reverse primer (749-bp fragment). Alignment and analysis of sequences from the samples was done with the software ChromasPro version 1.33 (Technelysium Pty Ltd, Tewantin, Australia).

The SNP in exon 1 of GDF9 (c.260G>A) was genotyped in a total of 97 ewes with litter size records (35 Ashgar, 29 Dubasi and 33 Watish) by PCR-restriction fragment length polymorphism (RFLP) analysis using the Hhal restriction enzyme. Its cleavage site (GCGC) occurs only in the presence of the G allele. For amplification of a 357-bp fragment containing the polymorphic position c.260G>A of GDF9 exon 1 and no additional $H$ hal cleavage site, these primers that were designed with Primer3 software were used: forward primer 5'-TGAGGCTGAGACTTGGTCCT-3' and reverse primer 5'-ATAAAGGAGTTGGCCCTGCT-3'. PCR amplification was carried out in a final volume of $25 \mu \mathrm{L}$, including $0.2 \mathrm{mM}$ dNTPs, $2 \mathrm{mM} \mathrm{MgCl}, 20 \mathrm{pmol} / \mu \mathrm{L}$ of each primer, $1.0 \mathrm{U}$ Go Taq Flexi Polymerase with $1 \times$ Colourless Go Taq Flexi buffer (PROMEGA, Madison, Wis, USA) and $50 \mathrm{ng}$ DNA template in a thermal cycler under these conditions: initial denaturation at $95{ }^{\circ} \mathrm{C}$ for $90 \mathrm{~s}$, followed by 35 cycles consisting of denaturation at $96{ }^{\circ} \mathrm{C}$ for $15 \mathrm{~s}$, annealing at $62{ }^{\circ} \mathrm{C}$ for $30 \mathrm{~s}$, extension at $72{ }^{\circ} \mathrm{C}$ for $60 \mathrm{~s}$, and a final extension at $72{ }^{\circ} \mathrm{C}$ for $5 \mathrm{~min}$. The resulting PCR product was incubated with Hhal in $10 \mu \mathrm{L}$ final volume as recommended by the manufacturer of the enzyme (New England Biolabs $\mathrm{GmbH}$, Frankfurt am Main, Germany). The resulting DNA fragments were separated on agarose gel (2.5\%) and visualized by staining with Midori green (Nippon Genetics Europe GmbH, Düren, Germany). Restriction fragment length polymorphism (RFLP) patterns were verified by sequencing PCR products with PCR forward primer as described before.

Genotype and allele frequencies were calculated for identified SNPs for all sheep and separately for each ecotype, and for the two groups of ewes with single and with more than a single lamb, respectively. Differences in genotype and allele frequencies between these two groups of divergent litter size were tested 
for significance with Fisher's exact test using the program IBM SPSS Statistics for Windows, Version 20.0. Armonk, NY: IBM Corp.

\section{Results and Discussion}

Sequencing the complete exon 2 of the GDF9 gene in a total of 28 sheep of the Ashgar, Dubasi and Watish ecotypes revealed four polymorphic positions: c.471C>T, c.477G>A, c.721G>A and c.978A>G. Minor allele frequencies for $T$ at position 471 and $G$ at position 978 were very low over all sheep $(0.05$ and 0.02 , respectively). These two SNP were monomorphic in Dubasi (c.471C>T) and Dubasi and Watish (c.978A $>\mathrm{G})$ sheep, respectively. The two other SNPs in exon 2 were polymorphic in all three ecotypes. For the SNP c. $477 \mathrm{~A}>\mathrm{G}$, the $A$ allele was predominant in Ashgar (0.44), whereas the $\mathrm{G}$ allele was the predominant allele in Dubasi and Watish ( 0.60 and 0.69 , respectively). Genotype frequencies for all polymorphic exon 2 SNPs for all sheep, for the different ecotypes and for ewes with a single lamb and for ewes with an average of more than a single lamb are given in Table 2. No significant differences in allele or genotype frequencies between the two groups differing in litter size were observed for any of these SNPs.

Table 2 Genotype frequencies of GDF9 exon 2 SNPs in Sudanese desert sheep, ecotypes, and in ewes with single and more than single lambs

\begin{tabular}{|c|c|c|c|c|c|c|c|c|c|c|c|c|c|}
\hline \multirow{3}{*}{ Sheep group } & \multirow{3}{*}{$\begin{array}{l}\text { Sheep } \\
(n)\end{array}$} & \multicolumn{12}{|c|}{ Genotypes of SNPs at positions } \\
\hline & & \multicolumn{3}{|c|}{$c .471 \mathrm{C}>\mathrm{T}$} & \multicolumn{3}{|c|}{ c. $477 \mathrm{G}>\mathrm{A}$} & \multicolumn{3}{|c|}{ c. $721 \mathrm{G}>\mathrm{A}$} & \multicolumn{3}{|c|}{ c. $978 A>G$} \\
\hline & & $\mathrm{CC}$ & CT & TT & $\mathrm{GG}$ & $A G$ & AA & GG & $A G$ & $\mathrm{AA}$ & AA & $A G$ & $\mathrm{GG}$ \\
\hline Ashgar & 10 & 0.80 & 0.20 & 0.00 & 0.10 & 0.60 & 0.30 & 0.70 & 0.20 & 0.10 & 0.90 & 0.10 & 0.00 \\
\hline Dubasi & 10 & 1.00 & 0.00 & 0.00 & 0.40 & 0.40 & 0.20 & 0.80 & 0.10 & 0.10 & 1.00 & 0.00 & 0.00 \\
\hline Watish & 8 & 0.88 & 0.12 & 0.00 & 0.50 & 0.38 & 0.12 & 0.88 & 0.12 & 0.00 & 1.00 & 0.00 & 0.00 \\
\hline All sheep & 28 & 0.89 & 0.11 & 0.00 & 0.33 & 0.46 & 0.21 & 0.79 & 0.14 & 0.07 & 0.96 & 0.04 & 0.00 \\
\hline \multicolumn{14}{|l|}{ Lambing type } \\
\hline Single & 15 & 0.93 & 0.07 & 0.00 & 0.33 & 0.40 & 0.27 & 0.80 & 0.13 & 0.07 & 1.00 & 0.00 & 0.00 \\
\hline More than single & 13 & 0.85 & 0.15 & 0.00 & 0.31 & 0.54 & 0.15 & 0.77 & 0.15 & 0.08 & 0.92 & 0.08 & 0.00 \\
\hline
\end{tabular}

Incubation of the 357-bp fragment containing the polymorphic position c.260G>A in GDF9 exon 1 with Hhal restriction enzyme resulted in fragments of 222 and 135 bp for genotype GG and in fragments of 357, 222 and 135 bp for genotype AG (Figure 2).

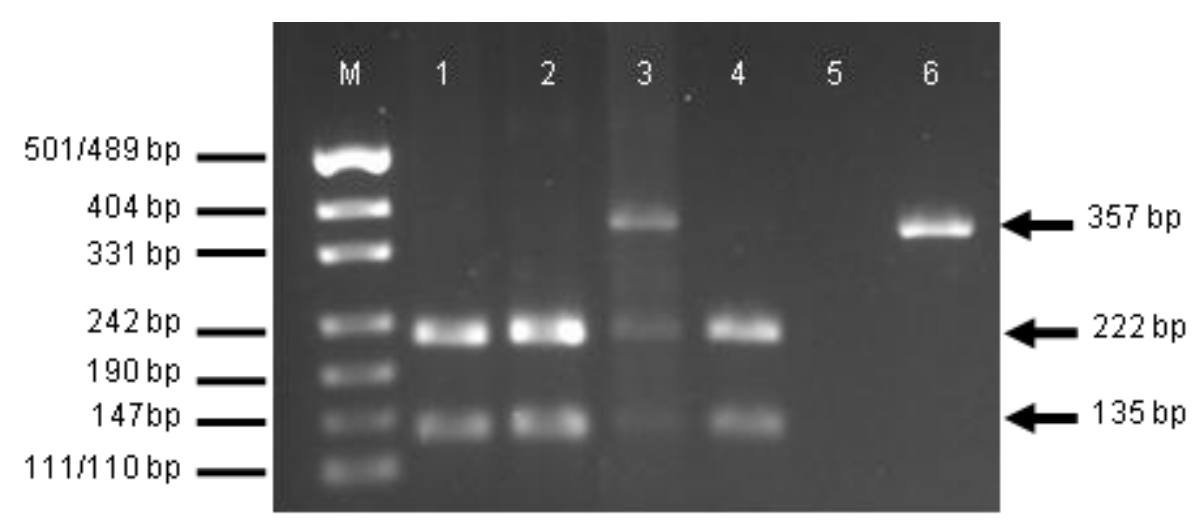

Figure 2 Determination of GDF9 genotypes at position c.260G>A by RFLP analysis 
$M=$ DNA size marker pUC19 DNA/Mspl (Thermo Fisher Scientific, Waltham, USA); $1-4=$ PCR products digested with Hhal (1, 2, 4 = genotype GG, 3 = genotype AG); 5 = negative control; 6 = undigested PCR product

For any sample, only a single 357-bp fragment (as expected for genotype AA) was observed after digestion with Hhal.

Allele and genotype frequencies calculated for the c.260G>A variant are given in Table 3. The frequency of the A allele was 0.10 among all genotyped sheep. In Ashgar, it was higher than in Dubasi and Watish ( 0.19 compared with 0.03 and 0.06 , respectively), but similar to these breeds, no sheep with the AA genotype was identified among the Ashgar sheep. Comparison of allele and genotype frequencies between ewes with a single lamb and with more lambs (see Table 3) revealed no significant differences.

Table 3 Allele and genotype frequencies of GDF9 exon 1 SNP c.260G>A in Sudanese desert sheep ecotypes, and in ewes with single/more than single lambs

\begin{tabular}{lcccccc}
\hline & & \multicolumn{5}{c}{ SNP c.260G>A } \\
\cline { 3 - 7 } Sheep group & \begin{tabular}{c} 
Sheep \\
\cline { 3 - 7 }
\end{tabular} & & \multicolumn{2}{c}{ Allele frequency } & \multicolumn{3}{c}{ Genotype frequency } \\
\cline { 3 - 7 } & & $\mathrm{A}$ & $\mathrm{G}$ & $\mathrm{GG}$ & $\mathrm{AG}$ & $\mathrm{AA}$ \\
\hline & & & & & & \\
Ashgar & 35 & 0.19 & 0.81 & 0.63 & 0.37 & 0.00 \\
Dubasi & 29 & 0.03 & 0.97 & 0.93 & 0.07 & 0.00 \\
Watish & 33 & 0.06 & 0.94 & 0.88 & 0.12 & 0.00 \\
All sheep & $\mathbf{9 7}$ & $\mathbf{0 . 1 0}$ & $\mathbf{0 . 9 0}$ & $\mathbf{0 . 8 0}$ & $\mathbf{0 . 2 0}$ & $\mathbf{0 . 0 0}$ \\
Lambing type & & & & & & \\
Single & 54 & 0.11 & 0.89 & 0.78 & 0.22 & 0.00 \\
More than single & 43 & 0.08 & 0.92 & 0.84 & 0.16 & 0.00 \\
& & & & & & \\
\hline
\end{tabular}

In this study, five known GDF9 variants (c.471C>T, c. $477 \mathrm{G}>\mathrm{A}, \mathrm{c} .721 \mathrm{G}>\mathrm{A}$ and c. $978 \mathrm{~A}>\mathrm{G}$ in exon 2 , and c.260G $>A$ in exon 1) were found to be polymorphic in at least one of the three Sudanese desert sheep ecotypes Ashgar, Dubasi and Watish. Only the SNP c.721G>A causes an amino acid substitution (p.Glu241Lys), which owing to the change of an acidic group with a basic group is a non-conservative one. However, as for all of the identified SNPs, this variant is located proximal to the furin protease cleavage site. Therefore, it was not unexpected that no significant association could be observed between the identified variants in exon 2 of GDF9 and litter size in Sudanese desert sheep ecotypes. Although the number of 28 sheep is very low for association testing, the authors refrained from genotyping the four polymorphic SNPs in exon 2 of GDF9 in a higher number of sheep because literature relating these variants to ovulation rate could not be found.

Also for the SNP c.260G>A in exon 1 of GDF9, no significant association was found with litter size in the sampled sheep. However, a higher frequency of the minor A allele was observed in Ashgar compared with Dubasi and Watish. From the 36 Ashgar sheep that were genotyped, 21 had single lambs and 15 had more than a single lamb on average. Because Ashgar sheep were observed to have a higher litter size than Dubasi and Watish (Sulieman et al., 1990), it may be interesting to genotype more Ashgar sheep for this SNP and to test for association with litter size within this breed. Results from Barzegari et al. (2010) indicate a possible effect of this SNP on ovulation rate/litter size. However, these results are based on very few sheep and should be taken with great care.

In addition to GDF9, the presence of other known major genes influencing ovulation rate could be tested for the desert sheep ecotypes analysed in this study. On the other hand, because these sheep do not show extraordinarily high litter sizes (compared with certain other breeds), the chance to identify such major gene variants seems to be low. By genotyping BMPR1B, BMP15 and GDF9 variants in five Tunisian sheep breeds (Barbarine, Queue Fine de L'Ouest, Noire de Thibar, Sicilo-Sarde and D'man) with litter sizes ranging 
from 1.14 (Queue Fine de L'Ouest) to 2.72 (D'man), Vacca et al. (2010) found an absence of all known ovulation-influencing alleles in these breeds. However, other breeds and genes are still open for research. A major gene variant that increases litter size in such a native African breed could be introduced in desert sheep ecotypes by classical intercrossing and backcrossing, and carriers of such a variant could then be identified and selected easily by genetic testing. Increased numbers of lambs have the potential to improve the livelihood and social status of the nomads. Of course, natural feed resources are limited in this region. However, it is more favourable to raise a larger number of lambs only once a year in the rain period than a lower number twice a year.

\section{Conclusion}

In summary, the authors concluded that five positions in GDF9 were found to be polymorphic in at least one of the Sudanese desert sheep ecotypes Ashgar, Dubasi and Watish. Except for the exon 1 variant c.260G $>A$, which had a higher frequency of the A allele in the more prolific Ashgar sheep compared with the less prolific Dubasi and Watish sheep, significant associations of these GDF9 variants with litter size were not observed. This suggests that the GDF9 variants that influence ovulation are absent in these Sudanese sheep ecotypes, and therefore cannot be used to increase litter size within this population of sheep.

\section{Acknowledgments}

The visit of A.S. Ali to the Department of Animal Breeding and Genetics at the Justus Liebig University of Giessen in Germany was financed by the German Academic Exchange Service (DAAD).

\section{Authors' Contributions}

A.S. Ali collected samples, executed sequencing and genotyping methods, analysed genotyping data and wrote significant parts of the manuscript. M.T. Ibrahim contributed to overall experiment design and collection of samples. M.M. Mohammed supervised and contributed to preparation of DNA samples. A.A. Elobied contributed to collection of samples and DNA extraction. G. Lühken supervised the establishment of sequencing and genotyping methods, contributed to data analysis and wrote significant parts of the manuscript. The manuscript has been read and approved by all named authors.

\section{Conflict of Interest Declaration}

The authors declare no conflicts of interest.

\section{References}

Albarella, S., Ciotola, F., Selvaggi, M., Dario, C., Licciardi, S., Scopino, G., Frate, D. \& Peretti, V., 2015. Analysis of major fecundity genes in autochthonous Laticauda and Bagnolese sheep breeds. Small Ruminant Res. 133, 118-122.

Barzegari, A., Atashpaz S., Ghabili K., Nemati Z., Rustaei M. \& Azarbaijani, R., 2010. Polymorphisms in GDF9 and BMP15 associated with fertility and ovulation rate in Moghani and Ghezel sheep in Iran. Reprod. Domest. Anim. 45, 666-669.

Bodensteiner, K.J., Clay, C.M., Moeller C.L. \& Sawyer, H.R., 1999. Molecular cloning of the ovine growth/differentiation factor-9 gene and expression of growth/differentiation factor-9 in ovine and bovine ovaries. Biol. Reprod. 60, 381-386.

Chu, M.X., Cheng, R.H., Fang, L. \& Ye, S.C., 2011. GDF9 as a candidate gene for prolificacy of Small Tail Han sheep. Mol. Biol Rep., 38, 5199-5204.

El-Hag, F.M., Fadlalla, B. \& Mukhtar, H.K., 2001. Some production characteristics of Sudan desert sheep under range conditions in North Kordofan, Sudan. Trop. Anim. Health Pro. 33, $229-239$.

Elvin, J.A., Clark, A.T., Wang, P., Wolfman, N.M. \& Matzuk, M.M., 1999. Paracrine actions of growth differentiation factor-9 in the mammalian ovary. Mol. Endocrinol. 13, 1035- 1048.

Hanrahan, P.J., Gregan, S.M., Mulsant, P., Mullen, M., Davis, G.H., Powell, R. \& Galloway, S.M., 2004. Mutations in the genes for oocyte-derived growth factors GDF9 and BMP15 are associated with both increased ovulation rate and sterility in Cambridge and Belclare sheep (Ovis aries). Biol. Reprod. 70, 900-909.

Juengel, J.L, Davis, G.H. \& McNatty K.P., 2013. Using sheep lines with mutations in single genes to better understand ovarian function. Reproduction 146, R111-R123.

MARFR, 2013. Ministry of Animal Resources, Fisheries and Ranges. Department of Statistic and Information. Khartoum, Sudan. Statistical Bulletin for Animal Resources, Issue No. 20, 13-16.

McNatty, K.P., Juengel J.L., Reader, K.L., Lun, S., Myllymaa, S., Lawrence, S.B., Western, A., Meerasahib, M.F., Mottershead, D.G., Groome, N.P., Ritvos, O. \& Laitinen, M.P., 2005. Bone morphogenetic 
protein 15 and growth differentiation factor 9 co-operate to regulate granulose cell function in ruminants. Reproduction 129, 481-487.

Montgomery, G.W. \& Sise, J.A., 1990. Extraction of DNA from sheep white blood cells, New Zeal. J. Agr. Res. 33, 3, 437-441.

Mukhtar, H.K., 1985. Constraints to desert sheep production in the sedentary and nomadic systems of North Kordofan. In: Annual Research Report (1984-85), (El-Obeid Research Station, Agricultural Research Corporation (ARC), Wad Medani, Sudan). Ed: Lazim M.E., pp. 40-55.

Nicol, L., Bishop, S.C., Pong-Wong R., Bendixen, C., Holm L.E., Rhind, S.M. \& McNeilly, A.S., 2009. Homozygosity for a single base-pair mutation in the oocyte-specific GDF9 gene results in sterility in Thoka sheep. Reproduction 138, 921-933.

Paulini, F., \& Melo, E.O., 2011. The role of oocyte-secreted factors GDF9 and BMP15 in follicular development and oogenesis. Reprod. Domest. Anim. 46, 354-361.

Silva, B.D., Castro, E.A., Souza, C.J., Paiva, S.R., Sartori, R., Franco, M.M., Azevedo, H.C., Silva, T.A., Vieira, A.M., Neves, J.P. \& Melo, E.O., 2011. A new polymorphism in the growth and differentiation factor 9 (GDF9) gene is associated with increased ovulation rate and prolificacy in homozygous sheep. Anim. Genet. 42, 89-92.

Souza, C.J.H., McNeilly, A.S., Benavides, M.V., Melo, E.O. \& Moraes J.C.F., 2014. Mutation in the protease cleavage site of GDF9 increases ovulation rate and litter size in heterozygous ewes and causes infertility in homozygous ewes. Anim. Genet. 45, 732-739.

Sulieman, A.H., Sayers, A.R. \& Wilson, R.T., 1990. Evaluation of Shugar, Dubasi and Watish subecotypes of Sudan desert sheep at El Huda National Sheep Research station, Gezira Province, Sudan. ILCA Research report, No. 18, Addis Ababa Ethiopia, pp. 30.

Untergrasser, A., Cutcutache, I., Koressaar, T., Ye, J., Faircloth, B.C., Remm, M. \& Rozen, S.G., 2012. Primer3 - new capabilities and interfaces. Nucl. Acids Res. 40, e115.

Vacca, G.M., Dhaouadia, A., Rekikb, M., Carcangiua, V., Pazzolaa, M. \& Dettoria, M.L., 2010. Prolificacy genotypes at BMPR1B, BMP15 and GDF9 genes in North African sheep breeds. Small Ruminant Res. $88,67-71$.

Vage, D.I., Husdal, M., Kent, M.P., Klemetsdal, G. \& Boman, I.A., 2013. A missense mutation in growth differentiation factor 9 (GDF9) is strongly associated with litter size in sheep. BMC Genetics 14, 1. 